\title{
Protocol
}

\section{Efficacy of yoga in controlling subclinical-hypothyroidism: a randomized controlled trial}

\author{
Rukamani Nair ${ }^{1}$, Ranjna Chawla ${ }^{2}$, Vipin Rai Sood ${ }^{3}$, B. K. Roy ${ }^{4}$, Somnath Mukherjee ${ }^{1 *}$
}

\author{
${ }^{1}$ Research and Development Division, Bapu Nature Cure Hospital and Yogashram, Delhi, India \\ ${ }^{2}$ Department of Biochemistry, Govind Ballabh Pant Institute of Postgraduate Medical Education and Research, New \\ Delhi, India \\ ${ }^{3}$ Department of General Medicine, Dr. Sood Clinic, Mayur Vihar Phase I, Delhi, India \\ ${ }^{4}$ Department of Endocrinology, Hormone Clinic, Laxmi Nagar, Delhi, India
}

Received: 17 February 2021

Revised: 28 March 2021

Accepted: 31 March 2021

\section{*Correspondence:}

Dr. Somnath Mukherjee,

E-mail: esomnath@gmail.com

Copyright: (C) the author(s), publisher and licensee Medip Academy. This is an open-access article distributed under the terms of the Creative Commons Attribution Non-Commercial License, which permits unrestricted non-commercial use, distribution, and reproduction in any medium, provided the original work is properly cited.

\section{ABSTRACT}

Background: A huge population in India is at high-risk of developing thyroid related disorders. Unhealthy lifestyle (lack of physical activity and consumption of junk food) is common among Indian population. Yoga is a form of physical activity and helps prevent many lifestyle disorders. The research question to be addressed by this randomised controlled trial (RCT) is whether yoga based intervention is effective in preventing overt hypothyroidism among sub clinical hypothyroid people in India as compared to untreated participants.

Methods: This is a single-blinded, two-arm, parallel-group RCT. Eligible participants should be aged 21-59 years, suffering from sub clinical hypothyroidism (serum thyroid stimulating hormone i.e. TSH level $4.2 \mathrm{mIU} / \mathrm{l}>\mathrm{TSH}$ level $<10 \mathrm{mIU} / \mathrm{l}$; T3 and T4 within normal range). At least 100 participants will be randomised either to the intervention group or the control group. Intermediate follow up at 3 month and final follow-up will be at six month post intervention. This study is designed to study the effect of yoga intervention on biochemical tests \{thyroid function tests (fT3, fT4 and TSH) \}, physical parameters (waist circumference, waist hip ratio, fat percentage and BMI) and psychological parameters \{quality of life (QOL) as assessed by World Health Organization (WHO)-QOL, sleep quality (assessed by PSQI) and depression (assessed by BDI-II) $\}$ in sub-clinical hypothyroid patients.

Conclusions: We are now conducting a RCT in Delhi, India to assess the efficacy of yoga in preventing progression of subclinical- hypothyroidism to overt hypothyroidism. If the yoga intervention used in this study is effective, it will be a low-cost feasible treatment for subclinical hypothyroidism in India.

Trial registration: Trial registration number is CTRI/2020/03/024023

Keywords: Yoga, Subclinical hypothyroidism, Thyroid stimulating hormone, Randomized controlled trial

\section{INTRODUCTION}

Thyroid dysfunction disorders are among the most common endocrine disorders across the globe. Studies indicate an estimated 42 million people in India suffer from thyroid diseases. ${ }^{1}$ Among various thyroid diseases, hypothyroidism is most prevalent. As per a study conducted in eight major cities (Bangalore, Chennai,
Delhi, Goa, Mumbai, Hyderabad, Ahmedabad and Kolkata) of India, the prevalence of hypothyroidism among adult population was $10.95 \%$. Prevalence was significantly higher in females $(15.86 \%)$ as compared to males $(5.02 \%){ }^{2}$ Among developed countries, the prevalence of overt hypothyroidism in the general population ranges from between $0.2 \%$ and $5.3 \%$ in Europe and $0.3 \%$ and $3.7 \%$ in USA. ${ }^{3}$ Increasing prevalence of 
thyroid disorders has significant social and economic consequences. ${ }^{4}$

As per the American thyroid association guidelines, subclinical hypothyroidism ( $\mathrm{SCH}$ ) refers to a condition where serum thyroid-stimulating hormone (TSH) levels are above the upper normal limit, despite normal levels of free serum thyroxin (fT3 and fT4). SCH occurs in $3 \%$ to $8 \%$ of the general population and is more common in women than men. $80 \%$ of SCH patients have a serum TSH of less than $10 \mathrm{mIU} / \mathrm{l}$.

Patients with $\mathrm{SCH}$ have a high rate of progression to clinically overt hypothyroidism $[2.6 \%$ for anti thyroperoxidase (TPO) antibodies negative patients and $4.3 \%$ for anti TPO positive patients]. ${ }^{5,6}$ Subclinical hypothyroidism may be associated with adverse cardiovascular events, cardiac dysfunction, lipid metabolism, neuromuscular dysfunction and neuropsychiatric symptoms. ${ }^{7-11}$

Yoga is an ancient mind-body discipline that originated in India. Yoga is considered safe, can be easily learnt and can be practiced both indoors and outdoors. ${ }^{12}$ Yoga can be practiced across all genders and age groups.

As per American college of sports medicine (ACSM) and the American heart association (AHA) classification, the intensity of holding most poses and of full yoga sessions ranged from light [less than 3 METS (metabolic equivalents)] to moderate-intensity (3-6 METS), with the majority classified as a light-intensity physical activity. ${ }^{13}$ As a moderate to low intensity exercise, yoga can have beneficial effects for people with hypothyroidism-and help in reducing negative symptoms associated with the disease, such as weight gain, depression, stiffness, joint aches and muscle weakness.

Mechanism underlying the beneficial effects of yoga on thyroid disorders has not yet been fully understood. Few assumptions suggest that yogic relaxation techniques may be producing psycho-somatic harmonization influencing the hypothalamic pituitary thyroid axis (HPT axis) and inducing a sense of calm due to hypo-metabolic activity. ${ }^{14}$ Rawal et al suggested that reduction in metabolic activity could be indirectly reducing the bodily demand for thyroxin. $^{15}$

Very few studies have been conducted on the effects of yoga on thyroid function. A study conducted by Swami et al reported significant improvement in forced expiratory volume (FEV), maximum voluntary ventilation (MVV) and inspiratory capacity (IC) following 21 days of pranayama and meditation, suggesting beneficial effect on pulmonary functions of hypothyroid patients along with conventional treatment. ${ }^{16}$ In another study, it was reported that yoga was valuable in helping the hypothyroid patients to manage their disease-related symptoms. Quality of life scores improved among female patients following one hour yoga session for one month. ${ }^{17}$
An RCT conducted by Nagendra et al reported reduction in TSH level, total cholesterol, low-density lipoprotein (LDL), triglycerides along with significant improvement in high-density lipoprotein (HDL) in hypothyroid patients. ${ }^{18}$ Another study conducted on 150 obese and hypothyroid female patients reported remarkable benefits from low-calorie diet along with yoga. ${ }^{19}$

Another RCT recently conducted to assess the effect of yoga on overt hypothyroid patients carried out in Delhi also reported beneficial effects on both biochemical parameters (TSH, T3, T4) as well as on psychological parameters (WHO-QOl, PSQI, BDI-II) following 6 months of yoga intervention. ${ }^{20,21}$ This will be the first clinical trial to study the effect of yoga on sub-clinical hypothyroidism. There is only one case report published by Bhavnani et al reporting the beneficial effect of yoga on a patient suffering from sub clinical hypothyroidism. ${ }^{22}$ To the best of our knowledge, this will be the first clinical trial to assess the effects of yoga based intervention on subclinical hypothyroidism.

The primary objective of this RCT is to study whether a yoga based intervention can prevent progression from $\mathrm{SCH}$ to overt hypothyroidism and revert $\mathrm{SCH}$ to euthyroid stage.

\section{METHODS}

\section{Study design}

This is a single-blind, two-arm, parallel-group RCT.

\section{Study location}

The study is conducted in the northern part of India at Bapu Nature Cure Hospital and Yogashram (BNCHY, Delhi).

\section{Screening and recruitment strategies}

Multiple screening approach is used to identify potential participants: advertisement through posters and pamphlets; screening camps at yoga centres, communities and religious places etc. and door to door visits in various nearby localities.

Individuals will be provided participant information sheet (describing the study and answering any questions), people interested in the study are requested to sign the written informed consent. Venous blood samples are collected from those providing the written informed consent. Serum TSH, T3 and T4 are estimated using standardised method (Table 1).

Those participants with TSH, T3 and T4 levels as per eligibility criteria are invited to BNCHY to sign informed consent form and are further re-assessed against the remaining eligibility criteria for the study. 
Table 1: Details of data collection.

\begin{tabular}{|c|c|c|c|c|c|}
\hline Parameter & Assessment details & $\begin{array}{l}\text { Screening } \\
\text { and } \\
\text { recruitment }\end{array}$ & Baseline & $\begin{array}{l}3^{\text {rd }} \text { month } \\
\text { assessment }\end{array}$ & $\begin{array}{l}\text { 6-month } \\
\text { assessment }\end{array}$ \\
\hline \multicolumn{2}{|l|}{ Eligibility assessment } & $\sqrt{ }$ & & & \\
\hline \multicolumn{2}{|l|}{ Socio-demographics } & & $\sqrt{ }$ & & \\
\hline \multicolumn{2}{|c|}{ Medical, surgical and family history } & & $\sqrt{ }$ & & \\
\hline \multicolumn{2}{|c|}{ Biochemical parameters } & & & & $\sqrt{ }$ \\
\hline Fasting plasma glucose & $\begin{array}{l}\text { Glucose oxidase-peroxidase } \\
\text { (GOD-POD) method }\end{array}$ & & $\sqrt{ }$ & & $\sqrt{ }$ \\
\hline $\begin{array}{l}\text { Glycated haemoglobin } \\
\text { (HbA1c) }\end{array}$ & $\begin{array}{l}\text { High-performance liquid } \\
\text { chromatography (HPLC) } \\
\text { method }\end{array}$ & & $\sqrt{ }$ & & $\sqrt{ }$ \\
\hline Thyroid function test (TFT) & CLIA method & & $\sqrt{ }$ & $\sqrt{ }$ & $\sqrt{ }$ \\
\hline Anti-TPO & CLIA method & & $\sqrt{ }$ & $\sqrt{ }$ & $\sqrt{ }$ \\
\hline $\begin{array}{l}\text { Aspartate aminotransferase } \\
\text { (AST) }\end{array}$ & Colorimetric enzymatic method & & $\sqrt{ }$ & $\sqrt{ }$ & $\sqrt{ }$ \\
\hline $\begin{array}{l}\text { Alanine aminotransferase } \\
(\mathrm{ALT})\end{array}$ & Colorimetric enzymatic method & & $\sqrt{ }$ & $\sqrt{ }$ & $\sqrt{ }$ \\
\hline Serum creatinine (SC) & Colorimetric enzymatic method & & $\sqrt{ }$ & $\sqrt{ }$ & $\sqrt{ }$ \\
\hline Physiological parameters & & & $\sqrt{ }$ & $\sqrt{ }$ & $\sqrt{ }$ \\
\hline Blood pressure & Omron HEM-7201 & & $\sqrt{ }$ & $\sqrt{ }$ & $\sqrt{ }$ \\
\hline Heart rate & Omron HEM-7201 & & $\sqrt{ }$ & $\sqrt{ }$ & $\sqrt{ }$ \\
\hline $\begin{array}{l}\text { Anthropometric } \\
\text { parameters }\end{array}$ & & & $\sqrt{ }$ & $\sqrt{ }$ & $\sqrt{ }$ \\
\hline Waist circumference & Seca 201 (measuring tape) & & $\sqrt{ }$ & $\sqrt{ }$ & $\sqrt{ }$ \\
\hline Hip circumference & Seca 201 (measuring tape) & & $\sqrt{ }$ & $\sqrt{ }$ & \\
\hline Weight & $\begin{array}{l}\text { Omron HBF-375-IN body } \\
\text { composition monitor }\end{array}$ & & $\sqrt{ }$ & $\sqrt{ }$ & $\sqrt{ }$ \\
\hline Height & Seca 206 (stadiometer) & & $\sqrt{ }$ & $\sqrt{ }$ & $\sqrt{ }$ \\
\hline Body mass index (BMI) & $\begin{array}{l}\text { Omron HBF-375-IN body } \\
\text { composition monitor }\end{array}$ & & $\sqrt{ }$ & $\sqrt{ }$ & $\sqrt{ }$ \\
\hline Fat percentage & $\begin{array}{l}\text { Omron HBF-375-IN body } \\
\text { composition monitor }\end{array}$ & & $\sqrt{ }$ & $\sqrt{ }$ & \\
\hline Current medications & & & $\sqrt{ }$ & $\sqrt{ }$ & $\sqrt{ }$ \\
\hline Diet & Time-recall: past 1-week & & $\sqrt{ }$ & $\sqrt{ }$ & $\sqrt{ }$ \\
\hline Tobacco usage & & & $\sqrt{ }$ & $\sqrt{ }$ & $\sqrt{ }$ \\
\hline Alcohol consumption & & & $\sqrt{ }$ & $\sqrt{ }$ & $\sqrt{ }$ \\
\hline Quality-of-life & $\begin{array}{l}\text { World Health Organization } \\
\text { Quality of Life (WHO-QOL) } \\
(\mathrm{BREF})^{33}\end{array}$ & & $\sqrt{ }$ & $\sqrt{ }$ & $\sqrt{ }$ \\
\hline Depression & $\begin{array}{l}\text { Beck depression inventory - II } \\
(\text { BDI-II })^{34}\end{array}$ & & $\sqrt{ }$ & $\sqrt{ }$ & $\sqrt{ }$ \\
\hline Sleep quality & $\begin{array}{l}\text { Pittsburgh sleep quality index } \\
\text { (PSQI) }\end{array}$ & & & $\sqrt{ }$ & \\
\hline Yoga practice & Time-recall: past 1-week & & $\sqrt{ }$ & $\sqrt{ }$ & $\sqrt{ }$ \\
\hline
\end{tabular}

\section{Eligibility criteria}

\section{Inclusion criteria}

Participants should be: aged 21-59 years; T3 level normal range $(2.0-4.0 \mathrm{pg} / \mathrm{ml})$; $\mathrm{T} 4$ level normal range $(0.8-1.8$ $\mathrm{ng} / \mathrm{dl}) ; 4.2 \mathrm{mIU} / \mathrm{l}>\mathrm{TSH}$ level<10 $\mathrm{mIU} / \mathrm{l}$, normal range (0.5-4.20 mIU/l); subclinical hypothyroidism patients with or without thyroid peroxidase (TPO) antibody test positive; willing and able to attend the intervention/control sessions on their own; and able to provide written informed consent. 


\section{Exclusion criteria}

Patients suffering from obesity grade III; TSH level >10 mIU/l; diabetes mellitus patients who are on Insulin and poorly controlled type-II diabetes mellitus patients where HbA1c $>10 \%$; patients who have a past history of severe cardiac dysfunction (atrial fibrillation, heart failure, myocardial infarction, uncontrolled hypertension, or stroke); patients with concurrent serious hepatic disorders defined as aspartate transaminase (AST) and/or alanine aminotransferase (ALT) $>3$ times of the upper normal limit; patients with concurrent serious renal disorders defined as serum creatinine $>1.5 \mathrm{mg} / \mathrm{dl}$; patients with concurrent serious pulmonary dysfunction; patient with cerebrovascular event during the last 12 months; women who are pregnant or lactating or planning pregnancy in near future; patient with any type of tumour or malignancy or any history of malignancy; and drugs and alcohol dependents.

\section{Randomisation process}

Participants found eligible as per the inclusion/exclusion criteria are randomised either to the yoga group or the control group according to a pre computer-generated randomisation schedule $(1: 1$, block randomisation, stratified by sex), done by an independent statistician. To avoid contamination, participants recruited from the same household, close relatives or friends are co-randomised to the same group. After randomisation, baseline data are collected. As it is a yoga based intervention where both participants and intervention providers cannot be 'blinded' to group allocation, the outcome assessor is an independent person not related to the trial and hence is blinded.

\section{Treatments}

\section{Intervention (yoga)}

After baseline investigations, intensive information, education and counselling about the disease and yoga practices will be given to all the participants. The intervention consists of an evidence based yoga schedule (Table 2). The yoga schedule includes breathing practices, loosening exercises, surya namaskar (sun salutation exercises), asana (yogic poses), kriyas, pranamayas (breathing practices), bandhas, and relaxation practices. The intervention has been systematically developed through reviewing earlier studies on effects of yoga practises on hypothyroidism and its symptoms. ${ }^{23-27}$ The intervention is delivered by a qualified and experienced yoga instructor, qualified with formal training provided on the intervention protocol. Yoga sessions are run as per convenience of the participants. Once participants complete the intervention period they will be encouraged to maintain the same healthy lifestyle in future. The duration of yoga therapy will be one hour. The frequency of treatment will be minimum twice a week for six months i.e. 72 sittings.
Table 2: Yoga schedule for sub clinical hypothyroidism.

\begin{tabular}{|ll|}
\hline Practice & Duration (min) \\
\hline Opening prayer & 3 \\
\hline Breathing practices & 5 \\
\hline Loosening exercise & 12 \\
\hline Suryanamaskara & 5 \\
\hline Asanas & 20 \\
\hline Kriya & 1 \\
\hline Pranayamas and bandha & 7 \\
\hline Relexation & 7 \\
\hline Total duration & 60 \\
\hline
\end{tabular}

\section{Control}

Currently, no intervention is available for people affected with sub-clinical hypothyroidism. The control group participants are receiving a diet chart. This is delivered by a different team member (i.e. not by the yoga instructor). The diet chart would ensure that control group participants feel that there are benefits to participation and minimize dropout from control group.

\section{Study parameters and data collection}

The parameters: symptom score, physical examination, blood chemistry. These parameters will be recorded at baseline, 3 months and 6 months; anti TPO antibody levels will be assessed at baseline and 6 months; psychological parameters will be studied by WHO-QOL Pittsburg sleep quality index (PSQI) and Beck depression inventory-II (BDI-II). These psychological parameters will be assessed at baseline, $3^{\text {rd }}$ month and $6^{\text {th }}$ month post intervention.

\section{Protocol adherence}

Adherence to the study protocol was determined by class attendance rates and participants' home practice rates as reported in their daily diary.

\section{Sample size estimation}

We assume that yoga at intervention group would have a significant change in biochemical tests [thyroid function tests (fT3, fT4 and TSH)], Physical parameters (waist circumference, waist hip ratio fat percentage and BMI, and psychological parameters [quality of life as assessed by WHO-QOL, sleep quality (assessed by PSQI) and depression (assessed by BDI-II)] at the end of the study. Based on similar studies, considering moderate effect size of $\mathrm{d}=0.57$ with a power of $80 \%$, two sided level of significance (alpha $=0.05$ ) and using two sample t-test for difference between two independent means, at critical value $\mathrm{t}=1.98$, non-centrality parameter $\delta=2.85$, for determining the study sample size, total of 40 patients are required for each group. But keeping in mind loss to follow up and drop out among patients $(20 \%)$ we have rounded it to 50 for each group. ${ }^{28,29}$ The sample size is estimated 
using statistical power analysis $\mathrm{G}^{*}$ Power Version 3.1.9.4, software.

\section{Data analyses}

The data will be analyzed by an independent statistician. The mean and variance for interventional and control groups will be calculated for quantitative parameters. Ttest will be used to analyze significant changes from basal to all end-points during the follow up and comparison between control and interventional groups. The statistical significance will be considered at $\mathrm{p}<0.05$ levels for all the parameters and the values will be expressed as mean \pm SD. Interim analysis is not planned.

\section{Ethics and other related issues}

Ethical approval is obtained from the Institutional Ethical Committee of Bapu Nature Cure Hospital and Yogashram, Delhi, India. Two languages (English and Hindi) are used to conduct the study.

\section{Serious adverse events}

Yoga is known to be safe. Information will be collected on any serious adverse events (hospitalization for more than 24 hours and death) occurring in participants during the intervention period. Based on clinical reasons, an independent clinician will determine, if there exists, relationship of such an event to the given intervention.

\section{Participant withdrawal}

Participants can withdraw from the study on their decision or if the principal investigator would find any valid reason to withdraw a participant. The participant will be informed for the reason for his/her withdrawal from the study.

The right of the participant of self-withdrawal will be informed through the participant information sheet and consent form at the time of registration. Even after a participant is withdrawn, the data collected to date may still be used in the final analysis.

\section{DISCUSSION}

Yoga is an ancient Indian therapy, having its root in India. Yoga has been a promising in the prevention and management of chronic diseases like thyroid, diabetes, and cardiac diseases. The government of India has noted its significance and hence set up the Ministry of Ayush to revive and scientifically develop and promote yoga as a form of therapy along with other traditional Indian therapies.

We are conducting this RCT in Delhi, India to assess the efficacy of yoga in preventing progression from subclinical hypothyroidism to overt hypothyroidism. The study started in January 2020 and we are aiming to finish the study by the end of December 2021 .
This study will be helpful to motivate patients to take up responsibilities of their own health mainly by controlling diet along with improvement in exercise schedule. As stated earlier there are higher chances of progression from subclinical hypothyroidism to overt hypothyroidism. It has been suggested that yoga may have a role in revitalizing thyroid function as well as improving psycho-neuroendocrine function on the whole. ${ }^{30,31}$ Though numerous studies have shown the psycho-physiological benefits and therapeutic potential of yoga. ${ }^{32}$ This study will specifically study the effectiveness of yoga on sub clinical hypothyroid condition among Indian population. The outcomes of this study will be an evidence based report of yoga intervention on thyroid disorder.

If the yoga intervention used in this study is effective, it will be a low-cost feasible treatment for subclinical hypothyroidism in India. Hypothyroidism is becoming a global health concern and has a significant cost of treatment. The outcomes of the study will also enable to conduct further larger trials to be conducted of other parameters not included in the present study.

\section{CONCLUSION}

To the best of our knowledge, this will be the first RCT to study the effect of yoga intervention on sub-clinical hypothyroidism. Subclinical hypothyroid patients have a high prevalence of converting to overt hypothyroid. The outcomes of this study will suggest whether yoga as an intervention is effective in: preventing progression from sub-clinical hypothyroid to over hypothyroid stage; and reverse sub-clinical hypothyroid to euthyroid stage. As such, there is no clinical therapy or treatment suggested for sub-clinical hypothyroidism. Based on the evidence from this study we aim to establish yoga as a simple and effective treatment for sub-clinical hypothyroid patients.

\section{ACKNOWLEDGEMENTS}

The authors would like to extend thanks to all who have participated in this study.

Funding: The study was funded by the Department of Science and Technology, Govt. of India

Conflict of interest: None declared

Ethical approval: The study was approved by the Institutional Ethics Committee

\section{REFERENCES}

1. Unnikrishnan AG, Menon UV. Thyroid disorders in India: An epidemiological perspective. Indian J Endocrinol Metab. 2011;15:78-81.

2. Unnikrishnan AG, Kalra S, Sahay RK, Bantwal G, John M, and Tewari N. Indian J Endocrinol Metab. 2013;17(4):647-52.

3. Taylor PN, Albrecht D, Scholz A, Gutierrez-Buey G, Lazarus JH, Dayan CM, Okosieme OE. Global epidemiology of hyperthyroidism and 
hypothyroidism. Nat Rev Endocrinol. 2018;14(5):301-16.

4. Møllehave LT, Linneberg A, Skaaby T, Knudsen N, Ehlers L, Jørgensen T, Thuesen BH. Trends in Costs of Thyroid Disease Treatment in Denmark during 1995-2015. Eur Thyroid J. 2018;7(2):75-83.

5. Gharib H, Tuttle RM, Baskin HJ, Fish LH, Singer PA, McDermott MT Subclinical thyroid dysfunction: a joint statement on management from the American Association of Clinical Endocrinologists, the American Thyroid Association, and The Endocrine Society. J Clin Endocrinol Metab. 2005;90:581-5.

6. Vanderpump MP, Tunbridge WM, French JM. The incidence of thyroid disorders in the community: a twenty-year follow-up of the Whickham Survey. Clin Endocrinol (Oxf). 1995;43(1):55-68.

7. Canaris G, Manowitz NR, Mayor G, Ridgway EC. The Colorado thyroid disease prevalence study. Arch Intern Med. 2000;160(4):526-34.

8. Danese MD, Ladenson PW, Meinert CL, Powe NR. Effect of thyroxine therapy on serum lipoproteins in patients with mild thyroid failure: a quantitative review of the literature. J Clin Endocrinol Metab. 2000;85(9):2993-3001.

9. Hueston WJ, King DE, Geesey ME. Serum biomarkers for cardiovascular inflammation in subclinical hypothyroidism. Clin Endocrinol. 2005;63(5):582-7.

10. Reuters VS, Teixeira Pde F, Vigário PS, Almeida CP, Buescu A, Ferreira MM, de Castro CL, Gold J, Vaisman M. Functional capacity and muscular abnormalities in subclinical hypothyroidism. Am J Med Sci. 2009;338(4):259-63.

11. Roberts LM, Pattison H, Roalfe A, Franklyn J, Wilson S, Hobbs FD, Parle JV. Is subclinical thyroid dysfunction in the elderly associated with depression or cognitive dysfunction? Ann Intern Med. 2006;145(8):573-81.

12. Anderson JG, Taylor AG. The metabolic syndrome and mind-body therapies: a systematic review. J Nutr Metab. 2011;276419.

13. Larson-Meyer DE. A Systematic Review of the Energy Cost and Metabolic Intensity of Yoga. Med Sci Sports Exerc. 2016;48(8):1558-69.

14. Wallace R K, Benson H, Wilson AF. A wakeful hypometabolic physiologic state. Am J Physiol. 1971;221(3):795-9.

15. Rawal SB, Singh MV, Tyagi AK, Selvamurthy W, Chaudhuri BN. Effect of yogic exercises on thyroid function in subjects resident at sea level upon exposure to high altitude. Int $\mathrm{J}$ Biometeorol. 1994;38(1):44-7.

16. Swami G, Singh S, Singh KP, Gupta M. Effect of yoga on pulmonary function tests of hypothyroid patients. Indian J Physiol Pharmacol. 2009;54(1):516.

17. Singh P, Singh B, Dave R, Udainiya R. The impact of yoga upon female patients suffering from hypothyroidism. Complement Therap Clin Pract. 2011;17(3), 2011:132-4.
18. Nilakanthan S, Metri K, Raghuram N, Hongasandra N. Effect of 6 months intense Yoga practice on lipid profile, thyroxine medication and serum TSH level in women suffering from hypothyroidism: A pilot study. J Complement Integr Med. 2016;13(2):18993.

19. Banerjee S. Study on Yoga Intervention along with Diet on Hypothyroidism Associated with Obesity among Sedentary Working Women in West Bengal. Int J Yoga Allied Sci. 2019;8(1).

20. Ranjna C, Rukamani N, Somnath M, Ibotombi MY, Sood VR. Outcome of six months of yogic practices on psychological parameters in patients suffering from hypothyroidism. IJAAR. 2020;4(6):513-28.

21. Chawla R, Nair R, Mukherjee S, Chawla R. Therapeutic Effects of Yoga in Managing Anthropometric Measures, Signs and Symptoms in Hypothyroid Patients. Int $\mathbf{J}$ Ayu Alt Med. 2019;7(3):99-107.

22. Balayogi BA, Sanjay Z, Madanmohan. Effect of yoga on subclinical hypothyroidism: a case report. Yoga Mimamsa. 2011;18(2):102-7.

23. Gowda S, Mohanty S, Saoji A, Nagarathna R. Integrated Yoga and Naturopathy module in management of Metabolic Syndrome: A case report. J Ayurveda Integr Med. 2017;8(1):45-8.

24. Bhavanani AB, Sanjay Z, Mohan M. Effect of Yoga on subclinical hypothyroidism: A case report. Yoga Mimamsa. 2011;43(2):102-7.

25. Nilakanthan S, Metri K, Raghuram N, Hongasandra N. Effect of 6 months intense Yoga practice on lipid profile, thyroxine medication and serum TSH level in women suffering from hypothyroidism: A pilot study. J Complement Integr Med. 2016;13(2):18993.

26. Saha M, Halder K, Tomar OS, Pathak A, Pal R. Yoga for Preventive, Curative, and Promotive Health and Performance. Translational Research in Environmental and Occupational Stress. Springer, New Delhi. 2014;169-80.

27. Saraswati, Satyananda S, Hiti JK. Asana pranayama mudra bandha. Bihar, India: Yoga Publications Trust. 1996.

28. Das S, Mitra K, Mandal M. Sample size calculation: Basic principles. Indian J Anaesth. 2016;60:652-6.

29. Shetty GB, Shetty B, Shetty P. Effect of short-term naturopathy and yoga intervention on anthropometric variables, lipid profile and thyroid profile in obese hypothyroid patients: a randomised controlled trial. Int J Basic Clin Pharmacol. 2020;9(2):247-53.

30. James F. Science Studies Yoga: A Review of Physiological Data. Honesdale,Penn: Himalayan International Institute of Yoga Science \& Philosophy. 1977.

31. Singh RH, Shettiwar RM, Udupa KN. Physiological and therapeutic studies on yoga. Yoga Rev. 1982;2(4):185-209.

32. Khalsa SBS. Yoga as a therapeutic intervention: a bibliometric analysis of published research studies. Indian J Physiol Pharmacol. 2004;48(3):269-85. 
33. Skevington SM, Lotfy M, O'Connell KA. The World Health Organization's WHOQOL-BREF quality of life assessment: Psychometric properties and results of the international field trial. A Report from the WHOQOL Group. Quality of Life Research: An Int J Quality Life Aspects Treatment, Care Rehabilitation. 2004;13(2):299-310.

34. Beck AT, Ward CH, Mendelson M, Mock J, Erbaugh J. An inventory for measuring depression. Arch Gen Psychiatr. 1961;4:561-71.
35. Buysse DJ, Reynolds CF 3rd, Monk TH, Berman SR, Kupfer DJ. The Pittsburgh Sleep Quality Index: a new instrument for psychiatric practice and research. Psychiatr Res. 1989;28(2):193-213.

Cite this article as: Nair R, Chawla R, Sood VR, Roy BK, Mukherjee S. Efficacy of yoga in controlling subclinical-hypothyroidism: a randomized controlled trial. Int J Clin Trials 2021;8(2):156-62. 